\title{
Experiência da Terapia Ocupacional no cuidado familiar em um serviço de Atenção Primária em Saúde ${ }^{1}$
}

\author{
Gisele Baissi ${ }^{\mathrm{a}}$, Bruno Souza Bechara Maxta ${ }^{\mathrm{b}}$ \\ aAcadêmica do Curso de Terapia Ocupacional, Centro Universitário Padre Anchieta, Jundiaí, SP, Brasil \\ ${ }^{\mathrm{b}}$ Mestre em Saúde Coletiva, Professor, Curso de Terapia Ocupacional, \\ Universidade Federal de Minas Gerais - UFMG, Belo Horizonte, MG, Brasil
}

\begin{abstract}
Resumo: A Terapia Ocupacional é apresentada como um núcleo de conhecimento envolvido no remodelamento e no fortalecimento da Atenção Primária no Sistema Único de Saúde brasileiro. Este artigo tem como objetivo descrever as intervenções do processo de Terapia Ocupacional no cuidado familiar supervisionado em uma Unidade Básica de Saúde no município de Várzea Paulista-SP. Através do método estudo de caso, os momentos do cuidado puderam ser descritos e analisados sob a perspectiva de narrativas da prática supervisionada da Terapia Ocupacional com uma família. Os resultados apresentam formas de intervenção que caracterizam o processo de Terapia Ocupacional centrado nas necessidades de saúde da família favorável à criatividade e ao protagonismo para mudanças em práticas de saúde na vida cotidiana. Através da realização de atividades ocupacionais e direcionadas para o autocuidado, a Terapia Ocupacional pode instrumentalizar a família no enfrentamento de adversidades no cotidiano.
\end{abstract}

Palavras-chave: Terapia Ocupacional, Assistência Domiciliar, Atenção Primária à Saúde, Saúde da Família, Centros de Saúde, Estudo de Caso.

\section{Occupational Therapy experience in family care in a primary health care service}

\begin{abstract}
Occupational therapy is presented as the core knowledge involved in the remodeling and strengthening of Primary Health Care in the Brazilian Unified Health Care System (Sistema Único de Saúde - SUS). In this study, we aimed to describe the interventions in the process of occupational therapy in supervised family care in a primary health care service in the municipality of Várzea Paulista, São Paulo state. In this case study, the moments of care were described and analyzed in light of narratives on the supervised practice of occupational therapy with a family. The results showed forms of intervention that characterize the process of occupational therapy focused on family health needs in favor of creativity and the role for changes in health practices in everyday life. Through the accomplishment of occupational activities directed to self-care, Occupational Therapy can aid families to cope with daily life adversity.
\end{abstract}

Keywords: Occupational Therapy, Home Nursing, Primary Health Care, Family Health, Health Centers, Case Studies.

\footnotetext{
Autor para correspondência: Gisele Baissi, Centro Universitário Padre Anchieta, Rua Adriano Pirani, 291, CEP 13210-430, Jundiaí, SP, Brasil, e-mail: gibaissi@hotmail.com

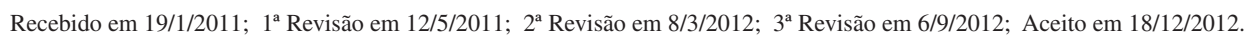




\section{Introdução}

O Sistema Único de Saúde (SUS) avança nas políticas de saúde territoriais e de humanização no país. Atualmente, o Ministério da Saúde aponta a Estratégia de Saúde da Família (ESF) como um conjunto de disposiçóes para inovar e qualificar o cuidado individual e coletivo na Atenção Primária em Saúde (APS).

Amparada pelo modelo assistencial da Vigilância da Saúde (TEIXEIRA, 1998), a ESF se propóe a atuar no território, a realizar ações dirigidas aos problemas de saúde de forma pactuada com a comunidade e a priorizar o cuidado familiar frente às situaçôes de saúde e doença identificadas. São características da ESF, entre outras: 1) a adstriçáo geográfica, populacional, epidemiológica e das práticas existentes nos territórios de abrangência de cada unidade de saúde; 2) o planejamento estratégico e situacional; 3) a articulação entre as açóes promocionais, preventivas e curativas de caráter interdisciplinar e intersetorial; 4) e a participação da comunidade nas açóes, projetos e ofertas de saúde. Sua proposta tende a superar a dicotomia ainda existente entre as práticas coletivas, comumente reconhecidas como de vigilância epidemiológico-sanitárias e de assistência ambulatorial na APS, fazendo uso de novas racionalidades de pensar e agir em saúde (PAIM, 2000).

Nesse contexto, a Clínica Ampliada apresenta-se como norte para o cuidado na ESF, pela proposiçáo de uma abordagem de cuidado centrada no compromisso do profissional com a pessoa de modo singular, a partir da construçáo compartilhada de diagnósticos e das corresponsabilidades terapêuticas no acolhimento, na escuta e no diálogo entre os profissionais, a família e a comunidade, para o provimento de projetos terapêuticos singulares e coletivos (BRASIL, 2007).

Através do estudo realizado com terapeutas ocupacionais atuantes na ESF do Estado de São Paulo, Jardim, Afonso e Pires (2009) identificaram que os Núcleos de Apoio a Saúde da Família (BRASIL, 2008) sáo espaços de atuaçáo desse profissional na APS. Envolvidos em equipes multiprofissionais, os terapeutas ocupacionais desenvolvem práticas de prevenção e de recuperação de doenças e de agravos e de promoçáo da saúde com crianças, jovens, adultos e idosos valorizando e intervindo sobre as atividades cotidianas. As práticas do terapeuta ocupacional se desenvolvem nos espaços internos do serviço de saúde, nos ambientes domiciliares e comunitários. Os recursos e materiais utilizados pelo profissional provêm tanto do serviço de saúde quanto do próprio usuário e da família.
De maneira complementar, Caldeira (2009, p. 81), em seu estudo sobre o processo de trabalho de terapeutas ocupacionais na Atenção Primária em Saúde do Município de São Paulo, identifica que a Terapia Ocupacional

[...] possibilita a construçấo de rede social, o atendimento às populaçôes com dificuldade de autonomia para Atividades de Vida Diária (AVD), o resgate da autoestima, o desenvolvimento da responsabilidade dos pacientes por seus cuidados e a solução de suas dificuldades, a melhora das funçóes corporais e atividades cotidianas, o contato-comunicação, a relação com o outro, a expressão e percepção de potencialidades, a aprendizagem sobre a melhor forma de lidar com as limitaçôes, a conscientização de açóes na prática, a retomada de papéis sociais e a diminuição de preconceitos em relação às pessoas excluídas.

Nesse contexto, as intervençóes do terapeuta ocupacional são, comumente, direcionadas às pessoas com deficiência e/ou sofrimento psíquico e abordam as suas atividades cotidianas, as relações interpessoais e a participação social. As práticas profissionais são dimensionadas pelo uso da atividade nos processos terapêuticos ocupacionais, cujo direcionamento é condicionado pelas necessidades da pessoa, pelos projetos de vida, pelos materiais e recursos da pessoa e pelo vínculo dos usuários com o profissional (CALDEIRA, 2009).

Nesses estudos, o terapeuta ocupacional demonstra o domínio na identificação de necessidades, na análise do cotidiano e na promoção de atividades ocupacionais, significativas, para a pessoa em seus espaços de vida, a partir de planos de cuidado pessoais ou comunitários. O profissional contribui, portanto, para o desenvolvimento da prática da pessoa e dos coletivos no cuidado em saúde.

Atenção Primária em Saúde demonstra constituir-se como um campo emergente de atuaçấo do profissional e, ao mesmo tempo, como espaço de produção de conhecimentos que inovam a identidade, os objetivos e os objetos de cuidado do terapeuta ocupacional.

Nesse sentido, como forma de contribuir para o debate sobre o tema, este artigo relata a experiência de um processo terapêutico ocupacional supervisionado em um contexto particular de organização de ensino-serviço para o cuidado familiar. 


\subsection{Objetivo}

Descrever as intervençóes do Processo de Terapia Ocupacional no cuidado familiar em uma Unidade Básica de Saúde.

\section{Metodologia}

Foi realizado um estudo de caso sobre a prática da Terapia Ocupacional em uma Unidade Básica de Saúde. O estudo está fundamentado nos métodos de investigação apresentados por Lakatos e Marconi (2009) e Yin (2005). Foram utilizados como instrumentos de identificação de informaçóes a observação participante e a documentação direta por meio de narrativas sobre a prática, visando qualificar as intervençóes do processo de Terapia Ocupacional no cuidado de uma família por uma dupla de estagiárias do último ano do curso de Terapia Ocupacional.

Como forma de análise dos dados, foram adotados os procedimentos de análise do discurso sobre as informaçóes terapêuticas ocupacionais identificadas no prontuário clínico desta família. Foram consideradas as categorias de análise Informaçōes pessoais e Histórias Clínicas dos familiares; Necessidades de saúde e problemas relacionados com a saúde; Objetivos; Abordagens teóricas e práticas em terapia ocupacional; Ambientes da prática em saúde; Intervençöes terapêuticas ocupacionais; e Resultados alcançados como elementos importantes para organizar e contextualizar o discurso, logo descrever as intervençôes do Processo de Terapia Ocupacional, sob a perspectiva de Sumsion (2003).

\section{Resultados e discussão}

\subsection{Características do campo de estágio}

Várzea Paulista é um município do Estado de São Paulo pertencente a Região de Saúde XVI. A sua população é estimada em 107.146 habitantes (INSTITUTO..., 2010) distribuídas em uma área geográfica urbana de $35 \mathrm{~km} 2$ conurbada com os municípios de Jundiaí-SP e Campo Limpo Paulista-SP. A sua fotografia urbana apresenta regiōes com acentuados acidentes geográficos: ruas íngremes, vales urbanizados e uma grande concentração demográfica. As casas sobrepostas e os inúmeros caminhos e vielas, com escadas longas, dificultam a acessibilidade urbana. Atualmente, o município busca a sua autossuficiência econômica, bem como a ampliação e a qualificação da assistência de seus serviços públicos.

A rede de saúde de Várzea Paulista é composta por serviços de baixa e média complexidade, representados por 12 Unidades Básicas de Saúde que recebem retaguarda de serviços municipais de especialidades médicas e odontológicas, de saúde mental adulto e infanto-juvenil, e hospitalares, bem como de outros equipamentos de cuidado da rede municipal e regional.

O modelo de atenção proposto pela gestão do município valoriza os saberes dos profissionais e as práticas de saúde existentes em cada território de saúde. Este modelo utiliza o planejamento coletivo e preconiza o uso de tecnologias na APS para o cuidado focado na prevenção e tratamento de agravos de doenças predominantes na populaçáo, logo para a promoção de saúde em respeito aos modos de vida das pessoas. A Clínica Ampliada, com as suas prerrogativas de apoio matricial na ESF (CAMPOS; DOMITTI, 2007), estão presentes no cotidiano dos serviços de saúde.

A Unidade Básica de Saúde (UBS) participante do estudo é formada por uma equipe multiprofissional composta por agentes de saneamento, auxiliar administrativo, auxiliar de saúde bucal, auxiliar de serviços gerais, cirurgióes dentistas, equipe de enfermagem, médicos e gerente. A principal proposta desse serviço é a adscrição territorial e o fortalecimento do vínculo com a população através do planejamento e do atendimento integral das necessidades de saúde na rede de serviços municipais e regionais, seguindo a Programação Anual de Saúde do município. Desde 2009, esta UBS é apoiada pelas equipes de estágio supervisionado dos cursos de Terapia Ocupacional, Fisioterapia e Nutrição do Centro Universitário Padre Anchieta - Unianchieta do município de Jundiaí.

\subsection{Contexto e intervenções do processo de Terapia Ocupacional}

\subsubsection{A identificação da família, as necessidades de saúde registradas e a perspectiva do projeto terapêutico ocupacional}

Em 2010, o estágio de Terapia Ocupacional direcionou as suas atividades para o apoio matricial de 12 famílias acompanhadas na UBS participante do estudo. Entre elas, a família Oliveira. 
Em setembro de 2010, o núcleo da família Oliveira era composto pelo casal José e Júlia.

No prontuário de José foram identificados registros, entre os anos de 1995 a 2010, realizados por profissionais médicos, enfermeiros e estagiários de Fisioterapia e Terapia Ocupacional. José, 75 anos, apresentava câncer de próstata com metástases múltiplas na regiâo abdominal associadas a diabetes mellitus e a hipertensão arterial sistêmica. Não há registros de sintomas de demência senil. Ele relatava dores frequentes nas costas, na região abdominal e nas articulações dos membros inferiores. No contexto de suas atividades cotidianas, expressava o sofrimento por ter dificuldades para movimentar-se, deslocar-se de sua cama para outro cômodo em seu domicílio. Queixava-se de muito cansaço durante a realização de atividades como alimentar-se, banhar-se e vestir-se. O José fazia uso contínuo de medicação. As práticas de saúde identificadas referiam-se aos cuidados da diabetes, da hipertensão arterial, dos sintomas relacionados à neoplasia e à funcionalidade nas atividades de vida diária.

No prontuário de Júlia, foram encontrados registros de consultas de rotina com médico clínico geral e uso de medicamentos relacionados à dor, bem como abordagens pontuais da equipe na mediação de conflitos entre ela e José, e entre o casal e os seus filhos. Havia relatos de que os encontros familiares eram permeados por discussóes e desentendimentos. Júlia se considerava abandonada pelos seus filhos. Ela almejava o apoio dos filhos para o cuidado do marido. Júlia relatava dificuldades na organizaçáo de informaçóes médicas, em adquirir e administrar a medicaçáo e para levar o marido às consultas de acompanhamento clínico.

Desses registros, as abordagens anteriores da Terapia Ocupacional centraram-se no apoio às práticas comumente realizadas pela equipe de enfermagem, somando-se a um plano de cuidado familiar que objetivava: 1) a organizaçáo da rotina do casal; 2) o conforto físico e a independência funcional do José; 3) o suporte emocional a Júlia; e 4) a reaproximação dos filhos do ambiente familiar.

A partir dessas informaçôes, em conjunto com a equipe de saúde, foi dado início à atualização do projeto terapêutico ocupacional para a família Oliveira, considerando o atual contexto familiar, os resultados e os desafios apontados pelos processos anteriores.

Para essa etapa foram consideradas as indicações de Siegman, Pinheiro e Almeida (2002), que orientam a programação e intervenção articulada com a equipe de saúde local, e a leitura de Mângia (2002) para a construção partilhada do processo de Terapia Ocupacional a partir do Modelo Canadense de Terapia Ocupacional.

Desse modo, o projeto de cuidado à família Oliveira se orientou: 1) pela abordagem centrada nos seus familiares; 2) pelo movimento de identificação de necessidades; 3) pela definição de objetivos em conjunto com os familiares; 4) pelo desenvolvimento de atividades cotidianas vinculadas às necessidades apresentadas, com a utilização de instrumentos e recursos provenientes do território; e 5) pela avaliação conjunta dos resultados alcançados.

\subsubsection{Primeiro momento com a família}

O primeiro momento com a família Oliveira objetivou o reencontro entre o supervisor de estágio e os familiares, a apresentação das novas estagiárias de Terapia Ocupacional e o diálogo sobre a situação atual de saúde da família. Para isso, optou-se pela visita domiciliar, pela possibilidade de conhecer familiares e as situações de saúde no espaço da vida prática, cotidiana. $\mathrm{O}$ agendamento dessa intervenção foi realizado pela equipe de saúde.

Quando chegamos no domicilio, fomos recebidos por Júlia, que relatou estar banhando José no leito. O banho no leito acontece quando José apresenta dificuldades para locomover-se até o banheiro - atividade realizada todos os dias, nas primeiras horas da manhã. Observamos que o quarto do casal possuía duas camas, uma cômoda e um armário de roupas. As duas camas eram separadas por uma cômoda onde ficava a $T V$, posicionada para José. A disposição desses objetos permitia pouca mobilidade e espaço para transferências. Permanecemos no quarto, conversando com o casal. José se mostrou bastante receptivo, relembrando as estagiárias do semestre anterior e relatando o quanto fora importante o trabalho realizado. Oferecemos a continuação dos atendimentos, com o propósito inicial de continuar com o trabalhado desenvolvido no semestre anterior, e de ajudar com as atividades que ele e a esposa desenvolviam no dia a dia. Ambos permitiram a continuidade do acompanhamento e combinamos encontros semanais. Ao terminarmos a conversa, Júlia nos mostrou a sua casa. Observamos que o domicílio tinha dois quartos, sala, sala de jantar, cozinha, um banheiro, lavanderia e uma área na frente da casa onde o casal criava dois papagaios e dois cachorros e também cuidava de várias plantas. Júlia informou que José passava o dia em seu quarto, assistindo televisão. Relatou as dificuldades que encontrava para organizar o cuidado do marido $e$ as atividades domésticas.

Nesse primeiro momento, foi iniciado diálogo sobre o histórico dos problemas e das necessidades de saúde dos familiares, particularmente, sobre 
a evolução dos sintomas e patologias associadas à situação do José. Em um segundo momento, conversou-se sobre as atividades que ambos realizavam de forma superar esses problemas.

As principais dificuldades apontadas foram as frequentes e fortes dores que José sentia nos membros inferiores, a dificuldade para ele transferir-se da cama, além de dúvidas na utilização do colchão casca de ovo. As atividades centravam-se no descanso, no uso da medicação, no controle da dieta e no deslocamento para o acompanhamento clínico em serviços de saúde.

Aproveitando o diálogo sobre o tema autocuidado, foram instruídos e realizados posicionamentos e mudanças de decúbito, considerando o modo como José realizava as atividades diárias em seu leito, como: conversar com sua mulher, assistir televisão, alimentação e medicação. Também foi orientado sobre a melhor forma de utilizaçáo do colchão, no intuito de melhorar-se a circulação sanguínea e prevenir escaras em pontos de pressão no corpo de José.

A partir desse encontro, a residência mostrou-se como um setting de inúmeras possibilidades práticas, um solo fértil para a análise e para o aprimoramento das atividades de saúde do casal. Sob o consentimento de José e Júlia, um novo processo de cuidado foi iniciado.

Munidos da abordagem canadense da Prática Baseada no Cliente (SUMSION, 2003), as estagiárias constituíram-se como facilitadores e articuladores das realizaçóes de José e Júlia em seu ambiente de vida, nesse momento, vinculados ao domicílio e envolvidos com os materiais e recursos do cotidiano familiar do casal. Os objetivos do trabalho foram definidos e priorizados em conjunto com eles, tendo como foco a promoção de atividades voltadas às necessidades apresentadas, os projetos de vida e de cuidado vigentes. Para isso foi elaborado um instrumento não padronizados para observação e registro de informaçóes sobre as atividades cotidianas do núcleo familiar considerando o Genograma e o Ecomapa Familiar (WENDT; CREPALDI, 2007) e a Medida de Performance Ocupacional (LAW et al., 2009), essa última voltada às narrativas sobre o cotidiano e aos problemas envolvidos nas áreas de desempenho ocupacionais de autocuidado, de produtividade e de lazer de José e de Júlia.

\subsubsection{Segundo momento}

$\mathrm{Na}$ residência da família,

Em sua cama, José se ateve em contar sobre a sua história. Falou sobre sua terra natal e sobre seu casamento com Júlia, que segundo ele foi realizado por um juiz em Alagoas, pois o pai de Júlia não aceitou o pedido de casamento, obrigando o casal a fugir para se casar. Casaram-se apenas no civil, gerando em Júlia a vontade de se casar na igreja, o que aconteceu, porém vários anos depois. José e Júlia são migrantes de Pernambuco e residem no estado de São Paulo há mais de 50 anos. Até se aposentarem, José trabalhava como pedreiro e Júlia era cozinheira. Ao falar da situação de doença de José, Júlia queixou-se das dificuldades com a organizaçâo dos exames de José. Acrescentou que não conseguia mais dormir durante a noite, pois ele sente muitas dores e também não consegue cozinhar e cuidar do marido ao mesmo tempo. Orientamos Júlia a cozinhar apenas uma vez no dia e em maior quantidade, armazenando uma parte desses alimentos em ambiente refrigerado, para aumentar sua durabilidade, e possibilitando o reaquecimento rápido para ingestão na próxima refeição. Júlia relatou-nos também sobre uma queda na rua, há cinco meses, da qual ela ainda sente dores; queixou-se também da ausência dos filhos. Ela gostaria de tê-los próximos para ajudá-la. Nesse momento fomos surpreendidas com a chegada de uma das filhas, que mora na casa ao lado. Ao nos apresentar, Júlia referiu-se a essa filha, falando que "ela não tem tempo para nos visitar" (sic Júlia). Essa fala gerou uma situação conflituosa entre mãe e filha. Ambas agrediram-se verbalmente. No intuito de trabalhar com a situação, propusemos um momento de conversa com a filha, que não aconteceu. José e Júlia novamente solicitaram ajuda.

$\mathrm{O}$ segundo atendimento apresentou um importante momento da vida do casal e foi conduzido pelos relatos das necessidades de saúde de Júlia em um momento de atividade de vida diária do casal.

Enquanto Júlia esquentava água para fazer um café, ela expressava as dificuldades em organizar suas atividades e o seu sofrimento com relação ao cuidado do marido e com relação ao comportamento dos seus filhos. A chegada de uma das filhas do casal, no momento da atividade, influenciou o comportamento agressivo de Júlia. A dupla de estagiárias buscou envolver a filha na atividade e restabelecer um equilíbrio nessa relação, com dificuldades. José e Júlia mostraram-se envergonhados e tristes com a situação ocorrida. O momento foi oportuno para o diálogo sobre a relação familiar e para o direcionamento do processo terapêutico.

A partir desse acontecimento, o plano de trabalho da Terapia Ocupacional se remodela. Reconhecendo: 1) a necessidade de qualificar a comunicação e a relação interpessoal dos familiares; 2) que José e Júlia vivem na residência e recebem visitas dos filhos e amigos periodicamente; 3) que as necessidades de 
saúde de José indicam dificuldades na realização de atividades de autocuidado e a situação de dor, na transferência e na locomoção em sua residência; 4) e que as necessidades de Júlia envolvem papel de cuidadora e o sofrimento emocional em 5) uma conjuntura familiar de conflitos interpessoais, os objetivos da Terapia Ocupacional, para além de fortalecer a independência e a autonomia de José em suas atividades de vida diária, foi proporcionar encontros familiares no intuito de aproximar valores, pensamentos e ideias que culminassem em novas práticas/atividades significativas capazes de responder às necessidades afetivas de cada integrante da família.

\subsubsection{Terceiro momento}

Júlia estava preparando leite para José, que estava sentado na cama, assistindo o noticiário. Enquanto esquentava o leite, o marido fez muitos comentários, demonstrando indignação sobre a violência e a corrup̧̧ão no país. Após tomar o leite sentado em sua cama, José começou a sentir dores e deitou-se sozinho. Oferecemos ajuda para posicioná-lo na cama de maneira favorável à respiração e à comunicação. Júlia demonstrou extrema necessidade de ser acolhida. Ela abordou o assunto dos exames e do afastamento dos filhos novamente, dando-nos margem para perguntar sobre a intercorrência da semana anterior. Em relação à filha, ela diz que, desde então, não se viram mais, alegando que os filhos "não têm jeito" (sic Júlia), demonstrando estar desanimad a e frustrada com o comportamento deles.

Nesse encontro, o sentimento de desânimo e de frustração do casal foram trabalhados pelas estagiárias como algo positivo para a aproximação afetiva de José e de Júlia, de maneira que ambos pudessem pensar juntos em como enfrentar essas dificuldades e necessidades.

A partir das histórias de vida, foi proposto o planejamento de uma atividade que contribuísse para a reflexão e o diálogo sobre a história, sobre os valores, sobre as pessoas e as relaçóes familiares. As estagiárias propuseram a confecção do mapa da família Oliveira.

\subsubsection{Quarto momento}

A proposta da confecção do mapa da família Oliveira foi retomada pelas estagiárias e aceita por José e Júlia, que participaram da atividade. Os materiais utilizados para a confecção do mapa foram trazidos pelas estagiárias: duas placas de papelão, pequenos pedaços quadrados de Etil Vinil Acetato, conhecido como EVA, azul (de $3 \mathrm{~cm} \times 3 \mathrm{~cm}$ ), representando os homens; e círculos de EVA vermelhos (de $3 \mathrm{~cm}$ de diâmetro) representando as mulheres. No processo, a tarefa do casal, auxiliado pelas estagiárias, era ordenar e identificar os integrantes de sua família na seguinte ordem: Bisavós, avós, pais e filhos, no caso composta por Júlia e seus irmãos, e por José e os irmãos dele. Construímos os mapas familiares separadamente: um para Júlia (Figura 1) e um para José (Figura 2).

Tanto José quanto Júlia demonstraram interesse e envolveram-se com a atividade.

Ao término da confecção do mapa genealógico e ao representar verbalmente a sua família, Júlia relatou ter sido adotada e que nunca conheceu sua mãe. Acrescentou que sempre quis tê-la conhecido. Relatou ainda que cresceu em Pernambuco, ao lado do pai e dos irmáos, também adotivos. Disse também não ter conhecido os avôs e bisavôs paternos e teve muitas dificuldades para lembrar o nome de integrantes de sua família. Foi tirada da escola muito cedo, aprendeu o nome de todas as letras mas não a ler e escrever. Aos 13 anos, casou-se escondida com José, pois o pai era contra o casamento. José relatou ter duas irmãs, as únicas vivas, de outro casamento da máe. Disse ter crescido

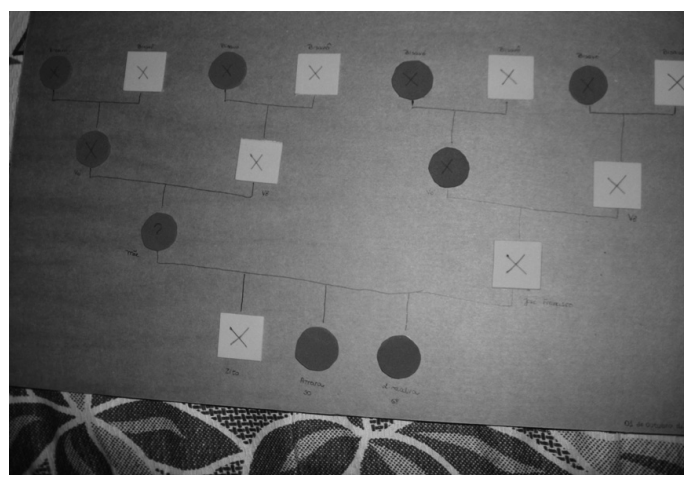

Figura 1. Mapa genealógico da família de Júlia.

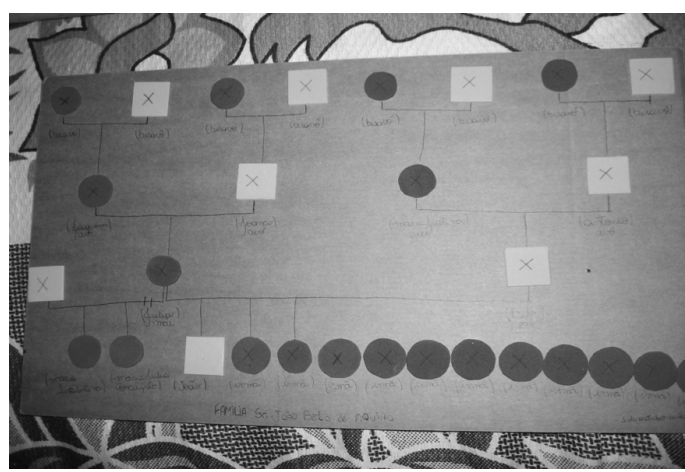

Figura 2. Mapa genealógico da família de José. 
convivendo com os avós, mas náo conheceu seus bisavós, pois já eram falecidos, e apresentou muitas dificuldades para lembrar o noms de integrantes de sua familia.

A atividade de confecção do mapa da família forneceu uma experiência prática nova para o casal e possibilitou diálogos para além da representação de seus integrantes e de como se davam as relaçóes entre eles. Ao desenvolver o mapa familiar, as estagiárias resgataram a história da família, dialogando sobre o tema afetividade/conflito, união/distanciamento entre as pessoas. A atividade serviu para ajudar o casal a delimitar os objetivos de vida, organizar as atividades diárias conjuntas e como encorajamento para novos protagonismos. Após o término da atividade, o casal se prontificou a juntar os dois mapas em um grande mapa familiar.

\subsubsection{Quinto momento}

Com o objetivo de confeccionar o grande mapa familiar a partir da atividade anterior:

Chegamos à casa do casal e encontramos Júlia cuidando dos afazeres domésticos. Ela estava calma ao nos receber. Suas preocupaçôes eram em relação à pintura da casa, que estava sendo realizada, e com José, que não estava bem. Após nos receber, Júlia relatou ter passado a noite com o marido no hospital, pois ele havia passado mal e desmaiado. José estava em seu quarto, deitado e aparentemente abatido, devido à noite no hospital. Ele nos relatou sobre o que havia acontecido, dizendo "estou preparado para os planos de Deus, mas tenho medo de morrer" (sic). Acolhemos os sentimentos de José, dialogando sobre sua força emocional e empenho em superar dificuldades. Logo em seguida, Júlia se juntou a nós perguntando sobre a continuação da atividade, então demos início à construção da segunda parte do mapa genealógico da familia.

Para esse mapa foram utilizados materiais iguais aos do mapa anterior. Nessa dinâmica, Júlia realizou a atividade em pé, ao lado da cama de José, que realizou a atividade deitado, posicionado sobre almofadas. Utilizamos como apoio para a placa de papeláo uma bandeja providenciada pelas estagiárias. Durante a realização da atividade, José e Júlia demonstraram confusáo ao tentar lembrar de todos os netos e bisnetos, pois têm uma quantidade grande de filhos e alguns dos netos e bisnetos eles náo conhecem, fato que, segundo o casal, os deixa muito tristes. José pertencente a uma familia com muitos irmãos, relatou que precisou trabalhar desde criança. Os auxiliamos com a disposição das peças e a colagem na placa.
Com a realização dessa atividade foi possível identificar todos os atuais integrantes da família (Figura 3). A realização da atividade ajudou José a trabalhar o seu sentimento de morte. O resgate das histórias de sua vida possibilitou recoloca-lo no papel de marido e pai - importantes para o direcionamento das atividades que dão sentido a sua vida.

O resultado do mapa genealógico estimulou o casal a sugerir a atividade seguinte: realização da renovaçáo dos votos do casal pela simulação de um novo casamento. Essa escolha demonstra uma atitude positiva de encorajamento e protagonismo importantes de serem exercidas em outros momentos do cotidiano familiar.

\subsubsection{Sexto momento}

Ao chegarmos à residência, Júlia nos atendeu e nos levou até o quarto de José. Esse momento teve como objetivo realizar a atividade da simulação do casamento com o objetivo de resgatar e valorizar a importância da união que se mantém após 52 anos de matrimônio. Cada estagiária ficou com um dos cônjuges durante a preparação para a simulação da cerimônia. Toda atividade foi filmada e registrada em fotos a pedido do casal. As imagens foram produzidas pelas estagiárias utilizando câmeras fotográficas digitais de propriedade delas mesmas. José se preparou para a atividade colocando uma gravata e arrumando a camisa que já vestia. Ele demonstrou-se ansioso para ver logo a esposa vestida de noiva. José também fez questão de ficar em pé para a cerimônia, apoiado em duas muletas. A preparação de Júlia consistiu em maquiagem e a colocação de um véu. Ela mostrou-se entusiasmada, escolhendo a maquiagem e se olhando a todo momento no espelho. Com o casal pronto, demos início à simulação de casamento para renovação dos votos. Ao som da marcha nupcial, em um dispositivo sonoro de um celular, levamos Júlia para o quarto onde já se encontrava o marido. Ela ficou surpresa ao ver que

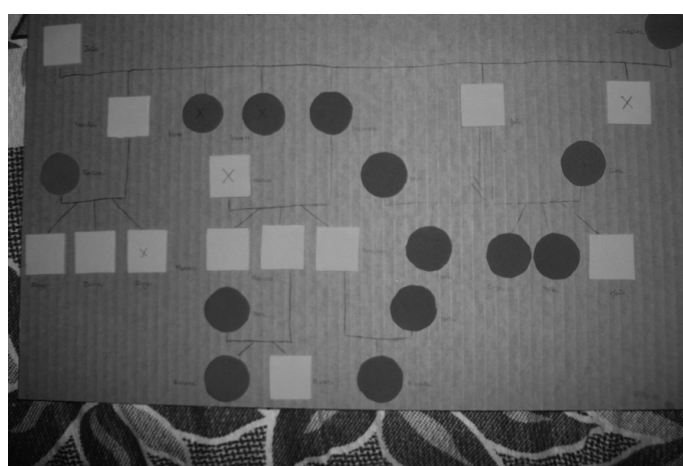

Figura 3. Mapa genealógico da família Oliveira. 
José estava em pé para recebê-la. Por serem religiosos, lemos uma passagem bíblica do Novo Testamento, que falava a respeito de amor. Tanto o casal como nós ficamos muito emocionados com a renovação dos votos. Após finalizarmos a atividade o casal falou a respeito da importância do amor e da união e do quanto gostaram da atividade, dizendo que "nunca ninguém fez isso por nós" e que "Deus enviou vocês para nós".

Amparados pelos referenciais de Moreno (1974), foi utilizado o instrumental do psicodrama para promover vivências significativas do casal. Notamos que, através desse recurso, pôde-se resgatar e valorizar uma questão intrínseca de Júlia, já que ela sempre se lamentava de não ter podido realizar uma cerimônia de casamento na igreja e de ter-se casado com José fugindo das famílias. Por outro lado, o casal reassumiu a identidade matrimonial, pois resgataram as alianças - há tempos guardadas junto com outros objetos pessoais de Júlia. Para essa atividade, Júlia destinou um período do seu dia à realização de cuidados pessoais, contribuindo para a valorização de sua identidade, valores e imagem corporal.

Outra reflexão suscitada pela análise do significado dessa atividade ocorreu com o comportamento de superação de José com relação aos obstáculos em suas atividades de vida diária e com relação às dores. Com pouca assistência, ele vestiu uma gravata sobre a camisa que já vestia e ficou de pé para receber a esposa. E ainda solicitou que o momento fosse registrado em fotografia e vídeo.

Foi identificado que os valores religiosos do casal estiveram presentes na atividade. Através da religião, ambos buscam respostas e apoio aos seus sofrimentos. Atualmente, são pelas palavras e pelas atividades de colegas da igreja que o casal recebe suporte social de cuidado.

\subsubsection{Sétimo momento}

Fomos recebidas por Júlia. Ao entrarmos no domicílio, encontramos seu. José sentado na cama, assistindo ao noticiário. Conversamos sobre a atividade realizada no atendimento anterior. Entregamos a foto feita a pedido do casal. Ficaram felizes por terem o momento registrado e colocaram a foto na estante da sala. Em nossa abordagem prática, retomamos a atividade do mapa genealógico da família, entregamos as placas agora compostas por todos os integrantes da família do casal. Ambos demonstraram desejo de pendurar o mapa na parede do quarto do casal. Informamos a eles que o vídeo produzido durante a atividade de simulação da renovação dos votos estava sendo editado e ficaria pronto na semana seguinte. José ficou satisfeito, pois desejava mostrar o video aos amigos que os visitavam frequentemente. Com o objetivo de identificarmos rede de suporte social e estimularmos a aproximação de amigos no cotidiano do casal propusemos então a montagem de um novo mapa que identificasse as pessoas que fazem parte do cotidiano da família, ideia aceita prontamente. Essa atividade consistia em apontar os personagens do cotidiano do casal. Dividimos uma folha de papel em áreas que tinham o nome dos principais serviços utilizados pelo casal, como: igreja, comércio, saúde. Inserimos também duas áreas compostas por familia e vizinhos. Junto ao casal, identificamos quais familiares e vizinhos constituem o dia a dia. Quando fizemos referência à filha que morava na casa ao lado, Júlia dispensou a necessidade de registrá-la no mapa, alegando que ela não os auxiliava. Explicamos que independentemente de eles receberem ou não auxílio da filha, poderíamos registrá-la na atividade, já que recebiam frequentemente a visita dela. Júlia a incluiu no mapa. Finalizamos a atividade enfatizando quem fazia parte da rede de apoio do casal. Esta atividade deu margem a que o casal se queixasse da assistência recebida da ambulância da prefeitura e da UBS, referindo a ausência de visitas que eram regularmente realizadas pela equipe de enfermagem, para aferição de pressão arterial e glicemia - que atualmente são realizadas por uma vizinha. Combinamos que no próximo atendimento levaríamos a gravação do vídeo da atividade de simulação do casamento.

Nesse processo de cuidado, a proposta de construçáo do ecomapa se configurou como um instrumento pertinente para análise e direcionamentos de atividades com as pessoas que fazem parte das redes sociais do casal. Na família Oliveira, o ecomapa (Figura 4) objetivou a identificação, o reconhecimento dos lugares, dos serviços e das pessoas que são referência para o casal, enfatizando suas redes de apoio - seja no auxílio à execução das atividades de vida diária, seja na manutençáo da casa e dos insumos, seja apenas no convívio social (SOUZA; KANTORSKI, 2009) - já que o casal possui vários amigos vizinhos.

O ecomapa em conjunto com o genograma familiar, para além do diagnóstico de uma determinada configuração familiar, contribuíram para que as estagiárias compreendessem as relaçóes da família no cotidiano e identificassem os espaços significativos na comunidade em que a vida de José e Júlia acontece, para assim ter mais elementos para avaliar e direcionar os caminhos do processo terapêutico ocupacional.

O momento da construçáo do ecomapa provocou em José a expressão de críticas sobre cidadania e direitos sociais. Ele defende as suas necessidades e o seu direito de saúde através da verbalização dos 


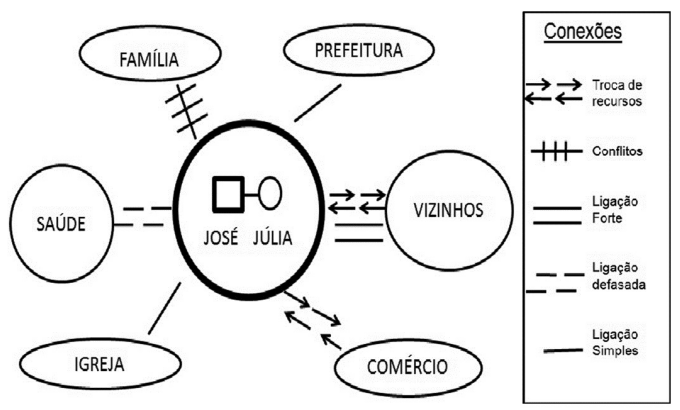

Figura 4. Ecomapa da família Oliveira.

seus sofrimentos e ideias para melhorar os serviços públicos. Segundo ele, para que consiga sucesso em suas atividades de cuidado de saúde, ele depende de sua mulher e de sua rede de suporte social, incluindo profissionais de saúde de sua unidade de referência. A não garantia do transporte para uma consulta ou tratamento ou mesmo a ausência de familiares e amigos nesses momentos colocam em risco a viabilidade dessas atividades, logo de seu projeto, e sentido, de vida.

As colocações de José evidenciam os posicionamentos de Siegman, Pinheiro e Almeida (2002), conforme os quais a condição experimentada por parte significativa das pessoas que sofrem de uma doença crônica ou degenerativa é a de confinamento doméstico, em que as atividades domésticas e de cuidado se configuram como eixo principal em torno do qual a vida se organiza. Nessa condição, a participação social da pessoa torna-se comprometida (CALDEIRA, 2009), orientando o empenho da Terapia Ocupacional voltada à construção de espaços e atividades que possibilitem trocas pessoais.

Como etapa do processo terapêutico, e movimento consentido pelo casal, as estagiárias contribuíram para a aproximação de uma vizinha no cuidado diário de José e para a reaproximação da equipe da UBS do cotidiano da família Oliveira.

\subsubsection{Oitavo momento}

Ao fim do processo de Terapia Ocupacional,

Fomos recebidas por Júlia. Encontramos José no quarto, deitado em sua cama, e observamos que havia uma pessoa pintando a porta do quarto ao lado. $\mathrm{Na}$ oitava e última visita realizamos a reprodução do vídeo do casamento. Utilizamos um vídeogame que reproduz DVD de uma das estagiárias como recurso, pois o casal possui apenas videocassete. Após organizarmos o ambiente, instalando o videogame, José sentou-se na cama com ajuda de assistência verbal de uma das estagiárias. Durante a reprodução do vídeo, ambos mostraram-se animados por relembrarem o momento e por se verem na televisáo, chamando o pintor para assistir junto. Ao finalizarmos a atividade, conversamos sobre todo o processo de acompanhamento do semestre. O momento de despedida, por conta do fim do estágio, estava próximo. Abordamos o assunto e conversamos sobre o vínculo terapêutico que foi construido, a receptividade do casal com as estagiárias, a importância e a ligação de cada atividade realizada. O resgate das vivências de marido e mulher e a informação de que houve uma reaproximação com a sua filha foram os assuntos trazidos pelo casal.

A reprodução do vídeo e a reaproximação da filha na vida domiciliar do casal finalizaram um processo que teve como eixo as ideias, os protagonismos, os afetos e as práticas. As estagiárias reconheceram, junto à família e posteriormente com a equipe de saúde, que os objetivos traçados foram parcialmente alcançados e que merecem a continuidade do acompanhamento pela UBS.

\section{Considerações finais}

Este artigo apresentou intervençóes do processo de Terapia Ocupacional no cuidado familiar em uma realidade de serviço da Atenção Primária em Saúde. O processo terapêutico ocupacional com a família Oliveira se desenvolveu sob a abordagem canadense da Prática Baseada no Cliente adaptada para o contexto familiar considerando as prerrogativas da ESF.

Nesse processo, José e Júlia configuraram-se como os familiares centrais do cuidado. Os atendimentos aconteceram no ambiente domiciliar, a partir da interação de recursos e desenvolvimento de atividades integrantes da realidade do casal, por vezes com a necessária adaptação pelas estagiárias.

O manejo das ocupações de José e Júlia, e a incorporação de atividades significativas à família contribuíram para as intervençóes do processo de saúde e doença, na prevenção de agravos e na promoção de saúde através de uma relação horizontal entre as estagiárias e os familiares. As estagiárias se constituíram, portanto, como facilitadoras e parceiras no desempenho de novas práticas de saúde correspondentes às necessidades apresentadas.

Nesse movimento, a identificação de necessidades e o estabelecimento de prioridades foram constantemente remodelados, respeitando, por um lado, os momentos e direcionamentos do casal e, por outro, as análises das atividades e os acontecimentos nas práticas realizadas. 
Entende-se que a breve descrição e análise dessa experiência apresenta parte do complexo processo terapêutico desenvolvido. No entanto, o seu movimento e as situaçóes nele destacadas contribuem para ampliar o debate sobre os fundamentos da Terapia Ocupacional e sobre a conduta do terapeuta ocupacional, em particular daquele em formação, no cuidado familiar na Atenção Primária em Saúde.

\section{Referências}

BRASIL. Ministério da Saúde. Secretaria de Atenção à Saúde. Núcleo Técnico da Política Nacional de Humanizaçâo. Clínica ampliada, equipe de referência e projeto terapêutico singular. Brasília: Ministério da Saúde, 2007. Disponível em: <http://bvsms.saude. gov.br/bvs/publicacoes/clinica_ampliada_equipe_ referencia_2ed_2008.pdf>. Acesso em: 10 jan. 2011.

BRASIL. Ministério da Saúde. Portaria GM no 154, de 24 de janeiro de 2008. Cria os Núcleos de Apoio à Saúde da Família - NASF. Diário Oficial da República Federativa do Brasil, Poder Executivo, Brasília, DF, 25 jan. 2008. Seção 1, n. 18. Disponível em: <http://dab. saude.gov.br/docs/legislacao/portaria154_24_01_08. pdf $>$. Acesso em: 10 jan. 2011.

CALDEIRA, V. A. Prática de Terapia Ocupacional em unidade básica de saúde na atenção às pessoas com deficiência. 2009. 170 f. Dissertação (Mestrado em Movimento, Postura e Ação Humana)-Faculdade de Medicina, Universidade de São Paulo, São Paulo, 2009.

CAMPOS, G. W. S.; DOMITTI, A. C. Apoio matricial e equipe de referência: uma metodologia para gestão do trabalho interdisciplinar em saúde. Cadernos de Saúde Pública, Rio de Janeiro, v. 23, n. 2, p. 399-407, 2007. http://dx.doi.org/10.1590/S0102-311X2007000200016 INSTITUTO BRASILEIRO DE GEOGRAFIA E ESTATÍSTICA - IBGE. Estatistica populacional São Paulo. Rio de Janeiro: IBGE, 2010. Disponível em: <http://www.ibge.gov.br/home/estatistica/populacao/ censo2010/tabelas_pdf/total_populacao_sao_paulo. pdf>. Acesso em: 19 jan. 2011.
JARDIM, T. A.; AFONSO, V. C.; PIRES, I. C. A Terapia Ocupacional na estratégia de Saúde da Família - evidências de um estudo de caso no município de São Paulo. Revista de Terapia Ocupacional da USP, São Paulo, v. 19, n. 3, p. 167-175, 2008.

LAKATOS, E. M.; MARCONI, M. A. Fundamentos de Metodologia Científica. São Paulo: Atlas, 2009.

LAW, M. et al. Medida Canadense de Terapia Ocupacional (COPM). Belo Horizonte: UFMG, 2009.

MÂNGIA, E. F. Contribuiçôes da abordagem canadense "prática de Terapia Ocupacional centrada no cliente" e dos autores da desinstitucionalização italiana para a terapia ocupacional em saúde mental. Revista de Terapia Ocupacional da USP, São Paulo, v. 13, n. 3, p. 127-34, 2002.

MORENO, J. L. História do Psicodrama. São Paulo: Cultrix, 1974.

PAIM, J. S. A crise de saúde pública e a utopia da saúde coletiva. Salvador: Casa da Qualidade, 2000.

SIEGMAN, C.; PINHEIRO, C. A.; ALMEIDA, M. C. Terapia ocupacional e pacientes acamados: açôes comunitárias. Revista de Terapia Ocupacional da USP, São Paulo, v. 13, n. 1, p. 37-43, 2002.

SOUZA, J.; KANTORSKI, L. P. J. A rede social de indivíduos sob tratamento em um CAPS ad: o ecomapa como recurso. Revista da Escola de Enfermagem da USP, São Paulo, v. 43, n. 2, p. 373-383, 2009. http://dx.doi. org/10.1590/S0080-62342009000200017

SUMSION, T. Prática baseada no cliente na Terapia Ocupacional. São Paulo: Roca, 2003.

TEIXEIRA, C. F. SUS, modelos assistenciais e vigilância da saúde. Informe Epidemiológico do SUS, Brasilia, v. 7, n. 2, p. 7-28, 1998.

WENDT, N. C.; CREPALDI, M. A. A utilização do Genograma como instrumento de coleta de dados na pesquisa qualitativa. Psicologia: Reflexão e Crítica, Porto Alegre, v. 21, n. 2, p. 302-310, 2008. http://dx.doi. org/10.1590/S0102-79722008000200016

YIN, R. K. Estudo de Caso: planejamento e métodos. Porto Alegre: Bookman Companhia Editora, 2005.

\section{Contribuição dos Autores}

Gisele Baissi: Responsável pela concepção do artigo, revisão e organização bibliográfica, realização do estudo de caso, das análises e discussão dos dados, redação e revisão final do texto. Bruno Souza Bechara Maxta: Responsável pela concepção do artigo, orientação técnica e metodológica do relato de experiência, análise e discussão dos dados e revisão final do texto.

\section{Notas}

${ }^{1}$ O estudo foi aprovado pelo Comitê de Ética em Pesquisa em Seres Humanos da instituição de ensino relacionada, sob protocolo n. 109/2010.

${ }^{2}$ Os nomes identificados neste estudo são fictícios, preservando a privacidade dos participantes da pesquisa. 